\title{
IMPACT OF THE PLANETARY BOUNDARY LAYER HEIGHT ON THE SURFACE AEROSOL OPTICAL AND MICROPHYSICAL PROPERTIES
}

\author{
Salvatore Romano, Maria Rita Perrone
}

\author{
Mathematics and Physics Department, University of Salento, via per Arnesano, 73100 Lecce, Italy \\ *Email: salvatore.romano@unisalento.it
}

\begin{abstract}
Lidar, nephelometer, and aethalometer measurements at the surface, co-located in time and space with Particulate Matter (PM) measurements, have been performed to investigate the impact of the daily evolution of the Planetary Boundary Layer (PBL) height on the aerosol optical and microphysical properties. Measurements were performed at a coastal site of southeastern Italy characterized by a shallow $(<1000 \mathrm{~m})$ PBL height. The Standard Deviation technique applied to the vertical profiles of both the lidar range corrected signal (RCS) and the linear volume depolarization ratio $\left(\delta_{\mathrm{r}}\right)$ has been used to determine the daily evolution of the PBL height and highlight benefits and limits of using RCS and $\delta_{\mathrm{r}}$ vertical profiles. It is shown that the PBL height, which drives the particle dispersion at the surface, significantly affects the optical and microphysical properties of the surface particles since the particle dispersion varies with their size and, consequently, the mean optical and microphysical properties of the surface particles are affected. The impact of meteorological conditions on the daily trend of the PBL height and the surface particle properties has also been highlighted.
\end{abstract}

\section{INTRODUCTION}

The characterization of the Planetary Boundary Layer (PBL) is of primary importance for climate, meteorological forecasts, pollutant dispersion, and air quality studies. Processes occurring within the PBL control energy, water vapour, and pollutant exchanges between the surface and the free atmosphere. The PBL experiences a marked diurnal cycle that depends on both the synoptic and the local weather conditions [1]. The PBL tends to be lower in depth at night, while during the day it tends to have a higher depth because of the wind speed and the air thickness, which vary as a function of temperature. Strong wind speeds allow for more convective mixing, which will cause the PBL to expand. At night, the PBL contracts because of the reduction of rising thermals from the surface and since cold air is denser than warm air (e.g., [2]). Consequently, the PBL height can be estimated from measurements of the mechanical turbulence, the temperature enabling convection, or the concentration of the atmospheric constituents. Several techniques have been applied to trace the daily trend of the PBL height [3]. Active remote sensing instruments such as lidars present advantages over the more traditional use of radiosondes for PBL studies (e.g., [4], [5]). In this study, the Standard Deviation (SD) technique applied to the vertical profiles of the lidar range corrected signal (RCS) and the linear volume depolarization ratio $\left(\delta_{\mathrm{r}}\right)$ has been used to determine the daily evolution of the PBL height and investigate its relationship with local meteorological parameters and aerosol properties at the surface. Main results will be presented and discussed by means of case studies.

\section{METHODOLOGY}

\subsection{Site description and UNILE lidar system}

Measurements have been performed in Lecce on the roof of the Mathematics and Physics Department of the University of Salento $\left(40.33^{\circ} \mathrm{N}\right.$, $18.11^{\circ} \mathrm{E}, 30 \mathrm{~m}$ a.s.1.). The monitoring site is located on a narrow and flat peninsular area 20 $\mathrm{km}$ away from both the Ionian and the Adriatic Sea and may be considered as representative of coastal sites of the Central Mediterranean away from large sources of local pollution [6]. The used ground-based lidar system, identified as UNILE (UNIversity of LEcce) lidar, operates within EARLINET (European Aerosol Research LIdar NETwork) since May 2000. It is currently composed by a Nd:YAG laser operating at 1064, 532 , and $355 \mathrm{~nm}$ at a repetition rate of $30 \mathrm{~Hz}$ and a $\mathrm{f} / 4$ Newton telescope [7]. 


\subsection{Nephelometer, aethalometer, and PM mass concentration measurements}

A light-emitting diode-based integrating nephelometer (model Aurora 3000, ECOTECH, Knoxfield, Australia) was used to measure the aerosol scattering and backscattering coefficients $\left(\sigma_{\mathrm{s}}\right.$ and $\beta_{\mathrm{s}}$, respectively) at 450,525 , and $635 \mathrm{~nm}$ with a temporal resolution of $5 \mathrm{~min}$. Then, an aethalometer model AE-31 (Magee Scientific, Berkeley, California, USA) was used to determine the aerosol absorption coefficient $\left(\sigma_{\mathrm{a}}\right)$ at seven wavelengths $(370,470,520,590,660,880$, and $950 \mathrm{~nm}$ ) with a temporal resolution of $5 \mathrm{~min}$. Both instruments were equipped with a PM2.5 sampling head [8]. A PM sampler (model FH 62 I-R, Thermo ESM Andersen Instruments $\mathrm{GmbH}$, Erlangen, Germany) fitted with a PM10 sampling head was used to investigate the daily evolution of the PM10 mass concentration.

\subsection{PBL height identification}

The turbulent nature of the mixing layer leads to a fluctuating boundary between the PBL and the free troposphere. Measurements of such fluctuations based on the standard deviation (SD) of lidar signals as a function of the altitude have been used to determine the PBL height (e.g., [9]). More specifically, the SD technique searches for the first maximum in the profile of the sum of the squares of the lidar signal deviations from the mean value over a selected time interval in order to detect the PBL height (e.g., [3]).

\section{RESULTS}

3.1 Daily trend of the PBL height and the meteorological parameters on 25 February 2016

Figure 1 shows by a color plot (a) the lidar RCS at $1064 \mathrm{~nm}$ and (b) $\delta_{\mathrm{r}}$ at $355 \mathrm{~nm}$ retrieved from measurements performed from 09:05 to 14:00 and from 16:54 to 17:55 UTC of 25 February 2016, from the ground level up to $2.4 \mathrm{~km}$. One observes that the aerosol particles were located at heights smaller than $\sim 2 \mathrm{~km}$ above ground level (agl) and within different aerosol layers, whose respective vertical profiles varied with the day hours. Fig. 1b highlights that the $\delta_{\mathrm{r}}$ values on average increased with the height, reaching values smaller than $\sim 710^{-3}$ at heights smaller than $\sim 950 \mathrm{~m}$ agl. Figure
2 shows by a color plot the SD of (a) the RCS and (b) $\delta_{\mathrm{r}}$ signals. Black dots identify the PBL heights retrieved from the SD technique. The PBL height from the SD of the RCS increased with the day hours up to $\sim 950 \mathrm{~m} \mathrm{agl}$ around 13:15 UTC and then decreased up to $\sim 450 \mathrm{~m}$ agl after sunset. The PBL heights with corresponding standard errors of the mean (SEM) retrieved from the RCS-SD (red dots) and $\delta_{\mathrm{r}}$-SD (blue triangles) are compared in Fig. 3 to better highlight the differences between the PBL heights from the two different signals. Figure 3 shows that the PBL heights retrieved from the RCS-SD were on average smaller than the corresponding ones obtained from the $\delta_{\mathrm{r}}-\mathrm{SD}$. The mean difference was equal to $\sim 120 \mathrm{~m}$. The observed differences could likely be due to the very low values of $\delta_{\mathrm{r}}$, as well as to the increase of $\delta_{\mathrm{r}}$ with the height, for altitudes larger than few hundred meters. Note also that we have observed a better agreement between the PBL height values retrieved from the SD of the two lidar signals at higher $\delta_{\mathrm{r}}$ values. Therefore, the SD technique applied to the $\delta_{\mathrm{r}}$ signals can lead to less reliable PBL heights if $\delta_{\mathrm{r}}$-values are rather small.

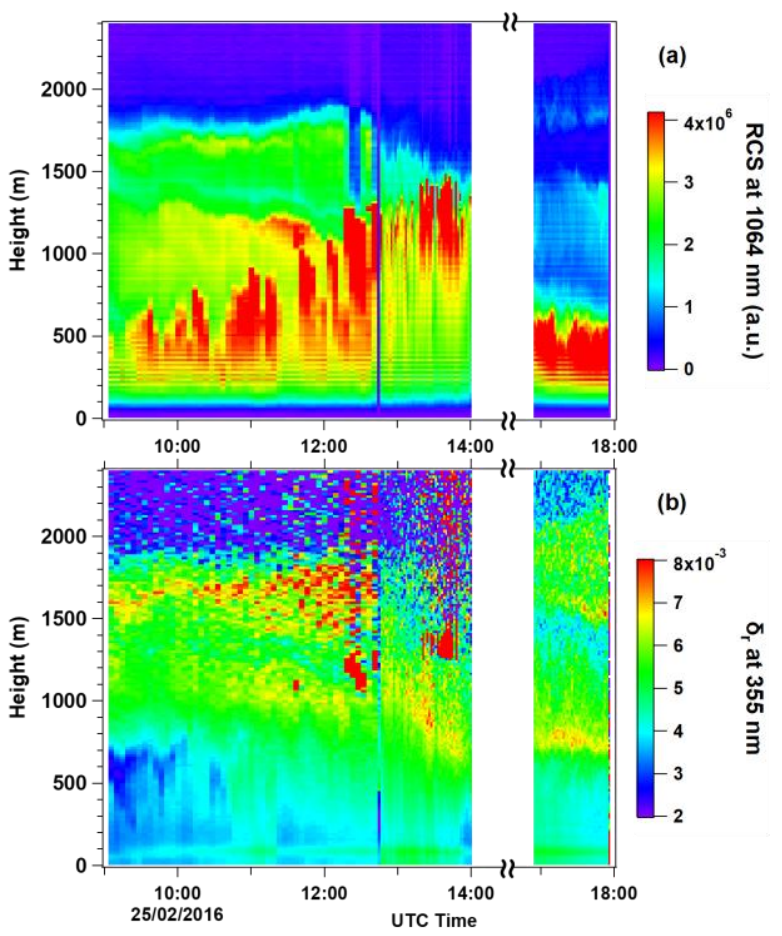

Figure 1 Color plot of the temporal evolution of (a) the range corrected lidar signal (RCS) at $1064 \mathrm{~nm}$ and (b) the linear volume depolarization ratio $\left(\delta_{\mathrm{r}}\right)$ at $355 \mathrm{~nm}$ on 25 February 2016. 


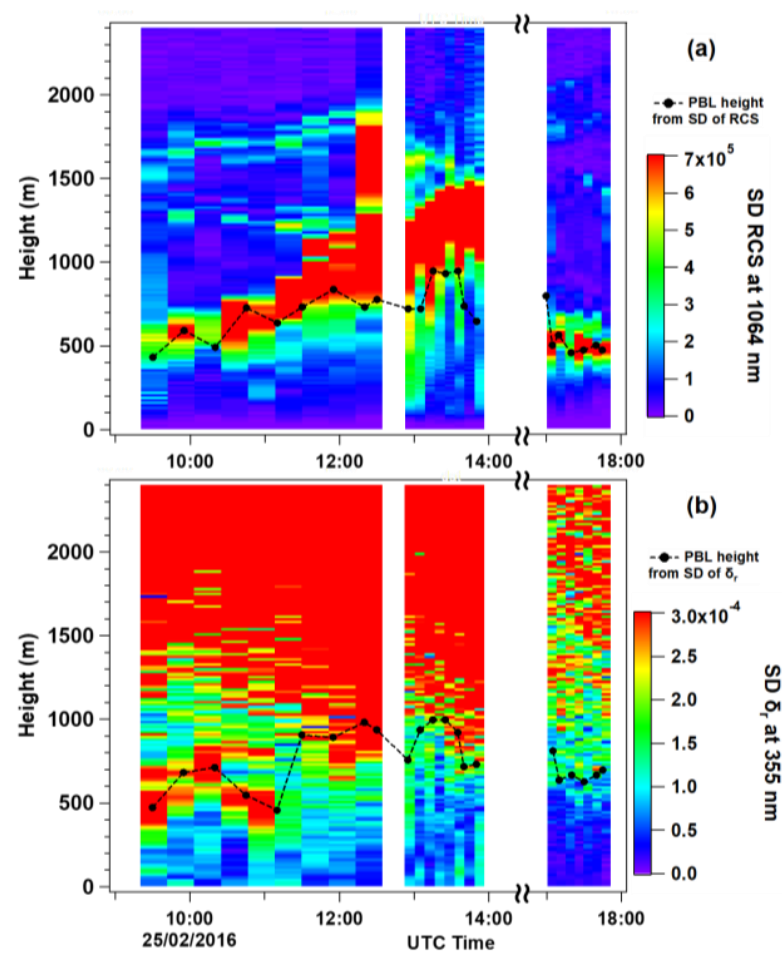

Figure 2 Color plot of the temporal evolution of the standard deviation (SD) of (a) the range corrected lidar signal (RCS) at $1064 \mathrm{~nm}$ and (b) the linear volume depolarization ratio $\left(\delta_{\mathrm{r}}\right)$ at $355 \mathrm{~nm}$ on 25 February 2016. Black dots identify the determined PBL heights.

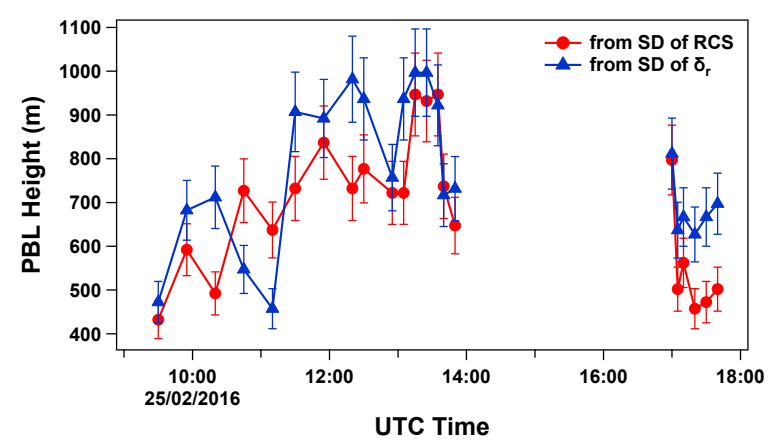

Figure 3 Time evolution of the PBL height (with the corresponding standard errors of the mean) retrieved from the RCS (red dots) and $\delta_{\mathrm{r}}$ lidar signals (blue triangles).

Figure 4 shows the daily evolution of temperature $(\mathrm{T})$, relative humidity $(\mathrm{RH})$, and wind speed (WS) values from a local meteorological station in addition to the daily trend of the PBL height (black dots). One observes from Fig. 4 that the PBL height increase/decrease is mainly driven by the WS increase/decrease, which in turn depends on the T time evolution.

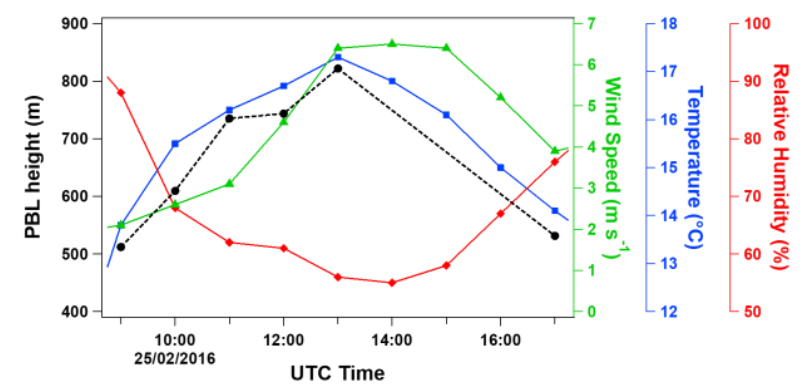

Figure 4 Temporal evolution of the hourly means of PBL height from RCS-SD (black dots), wind speed (green triangles), air temperature (blue boxes), and relative humidity (red diamonds).

\subsection{PBL heights and surface aerosol optical and microphysical properties}

The impact of the PBL height time evolution on the aerosol optical properties at the surface is clearly shown by Fig. 5, which shows the daily evolution of the aerosol scattering $\left(\sigma_{\mathrm{s}}\right)$ and absorption $\left(\sigma_{\mathrm{a}}\right)$ coefficients at $450 \mathrm{~nm}$ retrieved on 25 February 2016 from nephelometer and aethalometer measurements, respectively. The backscatter ratio $\left(\beta_{\mathrm{R}}=\beta_{\mathrm{s}} / \sigma_{\mathrm{s}}\right)$ calculated from the ratio of the aerosol backscatter coefficient $\left(\beta_{\mathrm{s}}\right)$ to $\sigma_{\mathrm{s}}$, both at $450 \mathrm{~nm}$, is also plotted in Fig. 5, in addition to the PBL heights (black dots). Figure 5 shows that $\sigma_{\mathrm{s}}$ and $\sigma_{\mathrm{a}}$ decrease with the increase of the PBL height, reaching the smallest values when the PBL height reaches its highest values. The backscatter ratio, which assumes lower values at higher PBL heights, indicates that the $\sigma_{\mathrm{s}}$ and $\sigma_{\mathrm{a}}$ decrease was likely due to the decrease of the fine-mode particle contribution at the surface. Indeed, the fine particles can be more efficiently dispersed than the coarse particles with the PBL height increase occurring during the central hours of the day [10]. The daily trend of the singlescattering-albedo SSA $=\sigma_{\mathrm{s}} /\left(\sigma_{\mathrm{s}}+\sigma_{\mathrm{a}}\right)$, shown in Fig. 6 , further supports this last comment. The increase of fine-mode particles, which on average are made by black carbon and/or carbonaceous species, is generally responsible for the decrease of the SSA. Therefore, Fig. 6 shows that the SSA increases with the PBL height up to $\sim$ midday and, then, decreases with the PBL height decrease, likely because of the increase of fine-absorbing particle contribution at the surface. The hourly means of the PM10 mass concentration retrieved from the PM sampler measurements are also plotted in Fig. 
6 (red diamonds). One observes that first the PM10 mass concentration assumed lower values $\left(\sim 30 \mathrm{~g} \mathrm{~m}^{-3}\right)$ when the PBL height reached its maximum hourly mean $(\sim 820 \mathrm{~m})$ at 13.00 UTC. Then, a decreasing trend of the PBL height was associated with an increasing trend of the PM10 mass concentration (up to $43 \mathrm{~g} \mathrm{~m}^{-3}$ ) until 17.00 UTC.

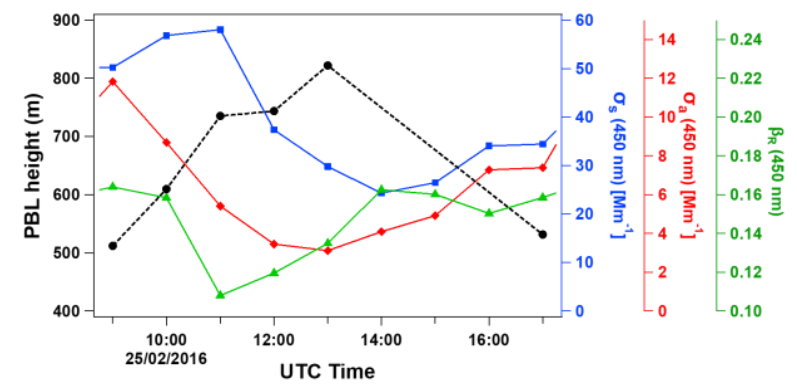

Figure 5 Temporal evolution of the hourly means of PBL height from the RCS-SD (black dots), aerosol scattering $\sigma_{\mathrm{s}}$ and absorption $\sigma_{\mathrm{a}}$ coefficient at $450 \mathrm{~nm}$ (blue boxes and red diamonds, respectively), and backscatter ratio $\beta_{\mathrm{R}}$ at $450 \mathrm{~nm}$ (green triangles) on 25 February 2016.

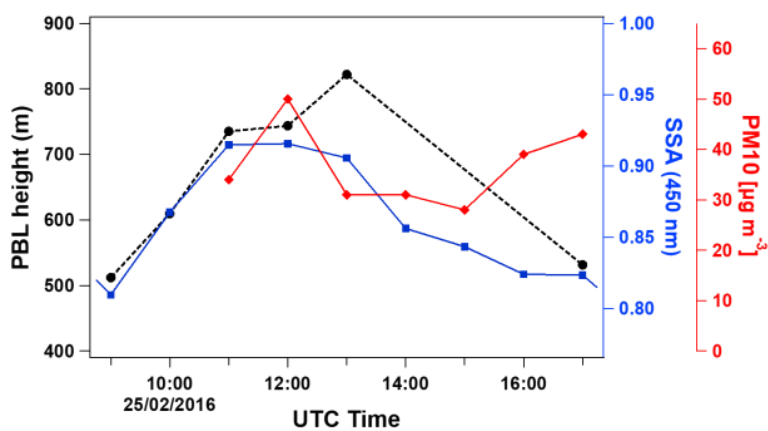

Figure 6 Temporal evolution of the hourly means of PBL height from the RCS-SD (black dots), single scattering albedo (SSA, blue boxes) and PM10 mass concentration (red diamonds) on 25 February 2016.

Figure 7 shows, as an example, the diurnal evolution of the hourly means of PBL height, $\sigma_{\mathrm{s}}$, $\sigma_{\mathrm{a}}$, and $\beta_{\mathrm{R}}$ calculated on 25 January 2016 to further highlight the relationships between the PBL height and the particle properties at the surface. Figure 7 also proves the inverse relation between the PBL height and $\sigma_{\mathrm{s}}, \sigma_{\mathrm{a}}$, and $\beta_{\mathrm{R}}$. In particular, one can observe that $\sigma_{\mathrm{s}}, \sigma_{\mathrm{a}}$, and $\beta_{\mathrm{R}}$ reached minimum values around midday, when the PBL height reached its maximum value of $\sim 550 \mathrm{~m}$, likely because of the dispersion mainly of the surface fine-mode particles.

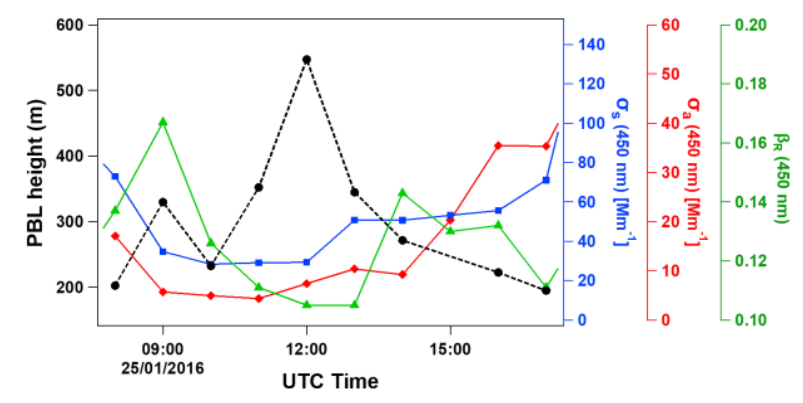

Figure 7 Temporal evolution of the hourly means of PBL height from the RCS-SD (black dots), aerosol scattering $\sigma_{\mathrm{s}}$ and absorption $\sigma_{\mathrm{a}}$ coefficient at $450 \mathrm{~nm}$ (blue boxes and red diamonds, respectively), and backscatter ratio $\beta_{\mathrm{R}}$ at $450 \mathrm{~nm}$ (green triangles) on 25 January 2016.

In conclusion, the results reported in this work have shown that the diurnal variations of the surface aerosol extensive $\left(\sigma_{\mathrm{s}}, \sigma_{\mathrm{a}}\right.$, and PM10 concentration) and intensive ( $\beta_{R}$ and SSA) properties are strictly related to the corresponding evolution of the PBL height. The benefits of using the RCS instead of $\delta_{\mathrm{r}}$ to calculate the PBL heights have also been highlighted.

\section{ACKNOWLEDGEMENTS}

S. Romano has carried out this work with the financial support of EARLINET as part of the ACTRIS Research Infrastructure Project by the European Union's Horizon 2020 research and innovation programme under grant agreements no. 654109 and 739530 (previously under grant agreement no. 262254) in the 7th Framework Programme (FP7/2007-2013).

\section{REFERENCES}

[1] R. B. Stull, Introduction to boundary layer meteorology. Kluwer, Dordrecht (1988).

[2] M. R. Perrone and S. Romano Atmos. Res. 213, 57-69 (2018).

[3] M. Collaud Coen, et al. Atmos. Chem. Phys. 14, 1320513221 (2014).

[4] F. De Tomasi and M.R. Perrone Atmos. Res. 80, 86-103 (2006).

[5] J.A. Bravo-Aranda, et al. Atmos. Chem. Phys. 17, 68396851 (2017).

[6] S. Basart, et al. Atmos. Chem. Phys. 9, 8265-8282 (2009).

[7] M. R. Perrone, et al. Atmos. Chem. Phys. 14, 1185-1204 (2014).

[8] S. Romano, et al. Atmos. Environ. 203, 35-47 (2019).

[9] H. Baars, et al. Atmos. Chem. Phys. 8, 7281-7296 (2008).

[10] M. R. Perrone, et al. Environ. Sci. Pollut. R. 22, 1657016589 (2015). 